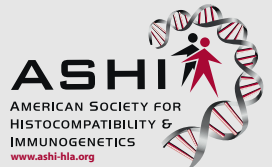

\title{
Association of rs1285933 single nucleotide polymorphism in CLEC5A gene with dengue severity and its functional effects
}

\author{
Caroline Xavier-Carvalho ${ }^{\mathrm{a}, \mathrm{b}}$, Renata Duarte da Silva Cezar ${ }^{\mathrm{c}}$, Naishe Matos Freire ${ }^{\mathrm{d}}$, \\ Carla Maria Mola de Vasconcelos ${ }^{c}$, Victor Edgar Fiestas Solorzano ${ }^{b}$, Thiago Gomes de Toledo-Pinto ${ }^{a}$, \\ Luciana Gomes Fialho $^{\mathrm{b}}$, Rodrigo Feliciano do Carmo ${ }^{\mathrm{e}}$, Luydson Richardson Silva Vasconcelos ${ }^{\mathrm{d}, \mathrm{f}}$, \\ Marli Tenório Cordeiro ${ }^{\mathrm{g}}$, Paulo Baptista ${ }^{\mathrm{d}}$, Elzinandes leal de Azeredo ${ }^{\mathrm{b}}$, Rivaldo Venâncio da Cunha ${ }^{\mathrm{i}}$, \\ Luiz José de Souza ${ }^{\mathrm{j}}$, Antonio Guilherme Pacheco ${ }^{\mathrm{h}}$, Claire Fernandes Kubelka ${ }^{\mathrm{b}}$, \\ Patrícia Muniz Mendes Freire de Moura ${ }^{\text {c,f }}$, Milton Ozorio Moraes ${ }^{\mathrm{a}, *}$
}

\footnotetext{
a Laboratório de Hanseníase, Instituto Oswaldo Cruz, Fundação Oswaldo Cruz, FIOCRUZ, Rio de Janeiro, RJ, Brazil

${ }^{\mathrm{b}}$ Laboratório de Imunologia Viral, Instituto Oswaldo Cruz - FIOCRUZ, Rio de Janeiro, RJ, Brazil

' Instituto de Ciências Biológicas, Universidade de Pernambuco, Recife, PE, Brazil

${ }^{\mathrm{d}}$ Faculdade de Ciências Médicas, Universidade de Pernambuco, Recife, PE, Brazil

e Colegiado de Ciências Farmacêuticas, Universidade Federal do Vale do São Francisco, Petrolina, PE, Brazil

${ }^{\mathrm{f}}$ Laboratório de Doenças Transmissíveis, Departamento de Parasitologia, FIOCRUZ, Recife, PE, Brazil

${ }^{g}$ LAVITE, CPqAM, FIOCRUZ, Recife, PE, Brazil

${ }^{\text {h }}$ Programa de Computação Científica (PROCC) - FIOCRUZ, Rio de Janeiro, RJ, Brazil

${ }^{i}$ Departamento de Clínica Médica, FM, Universidade Federal do Mato Grosso do Sul, Campo Grande, MS, Brazil

j Centro de Referência em Dengue e Faculdade de Medicina, Campos de Goytacazes, RJ, Brazil
}

\section{A R T I C L E I N F O}

\section{Article history:}

Received 21 December 2016

Revised 26 June 2017

Accepted 27 July 2017

Available online $\mathrm{xxxx}$

\section{Keywords:}

Dengue

CLEC5A

Polymorphisms

Severe dengue

SNPS

TNF

\begin{abstract}
A B S T R A C T
Outbreaks of the Zika, dengue, and chikungunya viruses, especially in the Americas, pose a global threat due to their rapid spread and difficulty controlling the vector. Extreme phenotypes are often observed, from asymptomatic to severe clinical manifestations, which are well-studied in dengue. Host variations are also important contributors to disease outcomes, and many case-control studies have associated single nucleotide polymorphisms (SNPs) with severe dengue. Here, we found that the TC genotype and T-carriers for SNP rs1285933 in the C-type lectin superfamily member 5 (CLEC5A) gene was associated with severe dengue in a Northern Brazilian population $(\mathrm{OR}=2.75$ and $\mathrm{p}$-value $=0.01, \mathrm{OR}=2.11$ and $p$-value $=0.04$, respectively). We also tested the functional effect of the CLEC5A protein and found that it is upregulated on the surface of human monocytes after in vitro dengue infection. CLEC5A was correlated with viral load inside the monocytes (Spearman $r=0.55, p=0.008$ ) and TNF production in culture supernatants (Spearman $r=0.72, p=0.03$ ). Analysis of mRNA in blood samples from DENV4-infected patients exhibiting mild symptoms showed that CLEC5A mRNA expression is correlated with TNF $(\mathrm{r}=0.67, \mathrm{p}=0.0001)$ and other immune mediators. Monocytes from rs1285933 TT/TC individuals showed lower CLEC5A expression compared to CC genotypes. However, in these cells, CLEC5A was not correlated with TNF production. In summary, we confirmed that CLEC5A is genetically associated with dengue severity outcome, playing a central role during the immune response triggered by a dengue viral infection, and rs 1285933 is a relevant SNP that is able to regulate signaling pathways after interactions between the dengue virus and CLEC5A receptors.
\end{abstract}

(c) 2017 Published by Elsevier Inc. on behalf of American Society for Histocompatibility and Immunoge-

netics.
* Corresponding author at: Oswaldo Cruz Institute - FIOCRUZ, Av. Brasil, 4365 Manguinhos, Rio de Janeiro 21040-360, Brazil.

E-mail address: milton.moraes@fiocruz.br (M.O. Moraes).

\section{Introduction}

The emergence of arboviruses such as Zika and chikungunya, along with a high prevalence of dengue viruses (DENV-1, DENV-2, DENV-3 and DENV-4) simultaneously circulating in tropical and subtropical countries, especially Brazil, has led to a 
demand for better understanding of the mechanisms by which coinfection or subsequent infections may lead to severe disease [1,2]. Dengue alone is estimated to occur at three times the registered rate [3]. Severe cases are believed to be more frequent in sequential infections with a distinct serotype, but some severe cases also occur in primary infections [4-7]. In the past decade, studies have shown that host variations also have an essential influence on dengue outcomes. Genetic epidemiological studies have identified single nucleotide polymorphisms (SNPs) that are associated with dengue outcomes, although most were not replicated independently. Nevertheless, genes associated with innate immunity, such as oligoadenylate synthetases (OASs), mannose-binding lectin (MBL2), MICB, and PLCE1, have been detected in genome-wide association studies (GWAS) and classic case-control designs [813].

C-type lectin superfamily member 5 (CLEC5A), a protein also known as MDL-1 (myeloid DAP-12 associating lectin 1), is expressed exclusively in myeloid cells [14]. CLEC5A does not appear to be responsible for viral entry into target cells, but plays a crucial role in inflammatory pathways through the association and consequent phosphorylation of the adaptor protein DNAXactivating protein of $12 \mathrm{kDa}$ (DAP12) [14-16]. DAP12 is a type I transmembrane adapter protein containing immunoreceptor tyrosine-based activating motifs (ITAMs). The agonist binds to the receptor associated with DAP12, inducing phosphorylation of tyrosine residues in Src kinases presenting on ITAMs, which recruits tyrosine kinase (Sik) and finally leads to a cellular signaling cascade [17,18]. ITAMs can recruit tyrosine kinases or tyrosine phosphatases [19,20]. During the canonical DAP12 signaling $[15,18]$ cytokines and chemokines are induced, including TNF, IL1, IL-6, IL-8, MIP1 $\alpha$ (21), RANTES, and IP10 [16,22].

Activation of CLEC5A by the dengue virus (DENV) results in septic shock mediated by TNF and nitric oxide in mouse models $[23,24]$. Additionally, monoclonal antibodies against CLEC5A can inhibit plasma leakage and hemorrhagic episodes, and can reduce mortality (16). Indeed, our previous findings in patients from Rio de Janeiro showed that CT/TT genotypes of $3^{\prime}$ near-gene rs1285933 SNP in CLEC5A was associated with risk of greater severity of dengue fever, and with higher serum TNF levels [10].

We previously searched for tag SNPs in CLEC5A and genotyped them in our first case-control study, but only rs1285933 was associated with dengue outcomes. In the present study, we aimed to replicate our previous genetic results for this SNP in a second Brazilian population, and to investigate the functional effect of CLEC5A by performing in vitro experiments and analyzing blood samples from dengue patients.

\section{Material and methods}

\subsection{Dengue patients and on study}

A total of 213 individuals aged $1-18$ years (97 females, mean age $8.3 \pm 4$ years; 116 males, mean age $9 \pm 4.7$ years) were included in this study. All individuals were hospitalized at the Oswaldo Cruz University Hospital-University of Pernambuco (HUOC-PE) between January 2010 and December 2011. All patients were positive for dengue based on ELISA IgM, IgG, NS1, or dengue PCR. Tests were performed in the Laboratory of Virology and Experimental Therapy (LAVITE) of the Research Institute Aggeu Magalhães, Oswaldo Cruz Foundation, Recife.

The patients were evaluated each day during their hospitalization for the following parameters: rash, days of fever, abdominal pain, bleeding, plasma leakage, pleural cavity effusion, hemoconcentration, hypotension, and platelet and leucocyte levels. Classification was performed according to WHO 2009, described previously [25]. Mild dengue patients presented with zero or only one alarm signal, and none presented with plasma leakage, cavitary effusion, or hemoconcentration. Severe dengue patients presented with hypotension, hemoconcentration, or effusion together with severe bleeding and two or more alarm signals.

\subsection{DNA extraction and genotyping}

DNA extraction was performed using the Wizard ${ }^{\circledR}$ Genomic DNA Purification Kit (Promega, Madison, WI, USA) following the protocol described by the manufacturer. The polymorphism rs1285933 (CLEC5A) was genotyped with allelic discrimination using real-time PCR with a TaqMan system (Invitrogen/ ThermoFisher).

\subsection{Dengue virus and titration}

The method of dengue virus propagation and titration has been described elsewhere [26]. Briefly, DENV serotype 2, strain Thailand 16681 [27], was propagated in Aedes albopictus cell lines (C6/36 cells) for seven days in Dulbecco's modified Eagle medium (Gibco/ThermoFisher, CA, USA) at $28^{\circ} \mathrm{C}$. Supernatants were then collected and centrifuged at $1.000 \mathrm{~g}, 4^{\circ} \mathrm{C}$ for $10 \mathrm{~min}$, and then aliquoted and stored at $-70{ }^{\circ} \mathrm{C}$. Alternatively, the supernatants were ultracentrifuged at $100,000 \mathrm{~g}$ for $1 \mathrm{~h}$ to a concentration of 20 times. Next, the supernatants were filtered, aliquoted, and stored at $-70{ }^{\circ} \mathrm{C}$. Titration was also performed in C6/36 using standard $\mathrm{TCID}_{50}$ (50\% tissue culture infective dose) [28].

\subsection{Cell culture and viral infection}

Blood from 24 healthy volunteers ( 19 females, age $34 \pm 7$ years; 5 males, age $32 \pm 5.4$ years) were collected in EDTA tubes (BD Bioscience, San Jose, CA, USA). Peripheral blood mononuclear cells (PBMCs) were isolated by Ficoll-Hypaque density gradient (FicollPaque Premium GE Healthcare Bioscience). Monocytes were purified using a Dynabeads Untouched Human Monocytes kit (Invitrogen/ThermoFisher) according to the manufacturer's instructions, then cultivated in RPMI-1640 (Invitrogen/Thermofisher, MD, USA) containing $10 \%$ fetal bovine serum (FBS, Hyclone) and $1 \%$ penicillin-streptomycin (Gibco) at $37{ }^{\circ} \mathrm{C}$ in $5 \% \mathrm{CO}_{2}$. Cells were adsorbed with the virus for $90 \mathrm{~min}$ in FBS-free medium. The medium was then replaced and cells were maintained for 24 or $48 \mathrm{~h}$ at $37{ }^{\circ} \mathrm{C}$ in $5 \% \mathrm{CO}_{2}$.

\subsection{Flow cytometry assays}

For extracellular labelling, cells were washed with $1 \%$ bovine serum albumin (BSA) and $0.1 \%$ sodium azide in PBS buffer. The cells were incubated for $30 \mathrm{~min}$ with unspecific blocking buffer (1\% BSA, 5\% autologous plasma, $0.1 \%$ sodium azide), then for 30 min with mouse anti-human/MDL-1 CLEC5A-PE (R\&D Systems, Minneapolis, MN, USA), anti CD14 PerCP (BD Bioscience), or IgG2b isotype (R\&D Systems). They were then fixed with wash buffer containing $2 \%$ paraformaldehyde (SIGMA).

For intracellular labelling, the cells were fixed with $2 \%$ paraformaldehyde and permeabilized with washing buffer containing $0.15 \%$ saponin. The cells were incubated for $60 \mathrm{~min}$ at $4{ }^{\circ} \mathrm{C}$ with anti-DENV complex, an antibody that targets all dengue serotypes (Millipore, Billerica, MA, USA), and for 30 min with IgG anti-mouse Alexa Fluor 488 (Molecular Probes/Life Technologies). The cells were acquired with an Accuri C6 cytometer (BD Bioscience) and analyses were performed using FlowJo ${ }^{\circledR}$ software (Treestar, Ashland, OR, USA). 


\subsection{TNF and NS1 viral quantification by ELISA}

TNF and non-structural viral protein (NS1) were quantified in cell culture supernatants using TNF ELISA kits (Peprotech, San Francisco, CA, USA) and NS1 Dengue ELISA kits (Panbio/Australia), respectively, according the manufacturer's instructions.

\subsection{Whole-blood patient samples}

Samples from 47 adult dengue patients were collected during the 2013 epidemic in the Brazilian states of Rio de Janeiro (RJ) and Mato Grosso do Sul (MS). Samples were collected in PAXgene tubes (PreAnalytiX/QIAGEN) and stored at $-70^{\circ} \mathrm{C}$. A sample was considered to contain dengue if it was positive for at least one of the following tests: IgM antibody-capture (MAC)-ELISA and IgGELISA [29], PCR [30], and NS1 Ag Strip (Biorad Laboratories, Marnes-La-Coquette, France). All patients were infected with DENV serotype 4 , and their clinical characteristics have been welldescribed previously [31].

\subsection{RNA extraction and cDNA Synthesis}

For in vitro assays, total RNA was extracted using TRIzol (Invitrogen/Life Technologies, CA, USA). RNA integrity was analyzed using $1.2 \%$ gel agarose electrophoresis. RNA from blood samples collected in PAXgene tubes was obtained using blood RNA kits (PreAnalytiX, QIAGEN/BD) according to the manufacturer's instructions. Subsequently, RNA integrity was analyzed by capillary electrophoresis using an Agilent 2100 Bioanalyzer and Agilent Total RNA kits according to the manufacturer's instructions (Agilent). RNA from the PAXgene tubes and in vitro assays were quantified in Qubit Fluorometric Quantitation (Thermo Fisher) using Qubit RNA HS assay kits according to the manufacturer's instructions. A total of $500 \mathrm{ng}$ of total RNA extracted for in vitro assays was reverse-transcribed in complementary DNA (cDNA) using OligodT (Invitrogen/Thermo Fisher) and Super Script III Reverse transcriptase (Invitrogen/Thermo Fisher). The same amount of total RNA from the PAXgene tubes was reverse-transcribed using the SuperScript ${ }^{\mathrm{TM}}$ VILO $^{\mathrm{TM}}$ cDNA Synthesis Kit (Thermo Fisher Scientific).

\subsection{Quantitative and multiplex real-time PCR}

PCR was performed using SYBR green in StepOnePlus (Thermo Fisher) under standard cycling conditions. The cDNA from blood samples was amplified with multiplex real-time PCR using EvaGreen (Applied Biosystems/Thermo Fisher) in a Fluidigm Biomark microfluidic system according to the manufacturer's instructions. The methodology is fully described elsewhere [32]. In all analyses, the ribosomal L13 protein (RPL13) gene was used as the housekeeping gene, and data were analyzed by $2^{-\Delta \mathrm{Ct}}$.

\subsection{Statistical analysis}

Non-parametric and paired Wilcoxon's $t$-test or the Friedman test were applied when adequate. Correlations were performed using Spearman's r-test. All analyses were conducted with Prism software 6.0 (GraphPad Software Inc., San Diego, CA, USA). As the gene expression analysis involved samples collected a single time, we used $2^{-\Delta \mathrm{Ct}}$ instead of $2^{-\Delta \Delta \mathrm{Ct}}$ because there were no samples to be used as calibrators. Therefore, we decided to perform all analyses using the same parameters.

The rates of mild versus severe cases were compared with logistic regression adjusted for IgG positivity, sex, and age. Hardy Weinberg equilibrium (EHW) was tested using chi-squared tests. Analyses were performed with the genetic $\mathrm{R}$ package, version 2.11.1 [33].

\section{Results}

\subsection{SNP analysis}

More than $80 \%$ of the patients were IgG-positive (data not shown). However, it is noteworthy that most of the patients recruited for this study were children during the epidemic, suggesting a lower likelihood of previous infections. Even so, we included IgG (positive or negative) as a covariate in the logistic regression model.

We confirmed that rs1285933 SNPs did not deviate from the Hardy Weinberg Equilibrium (HWE) (data not shown). We found that the heterozygous genotype $\mathrm{CT}(\mathrm{OR}=2.75, \mathrm{p}$ value $=0.01)$ and $\mathrm{T}$ carriers $(\mathrm{CT}+\mathrm{TT})(\mathrm{OR}=2.11$, p value $=0.04)$ were associated with the severe group Table 1.

\subsection{CLEC5A protein expression in DENV-infected monocytes}

After finding that CLEC5A was associated with severe dengue in a second independent population of Brazilian children, we decided to investigate CLEC5A expression during dengue infections to explore the functional effects of the rs1285933 SNP.

Monocytes purified from healthy adult volunteers' blood were infected or not with dengue virus (serotype 2, strain 16681) for 24 or $48 \mathrm{~h}$. Using flow cytometry analysis, after doublet exclusion, monocytes were selected in the morphological area (Fig. S1).

We observed that CLEC5A labelling could be detected homogeneously $24 \mathrm{~h}$ and $48 \mathrm{~h}$ after DENV infection (Fig. 1A). When comparing 24-h-infected cells with uninfected cells (NI), we observed increased CLEC5A protein detection on cell surfaces (Fig. 1B). CLEC5A mRNA levels were also higher in DENV-infected monocytes at $24 \mathrm{~h}$ (Fig. S2). DENV intracellular labelling was also correlated with CLEC5A detection at $24 \mathrm{~h}$ of infection (Fig. 1C).

Table 1

Genotype, allelic, and carrier frequencies for rs1285933 SNP in CLEC5A.

\begin{tabular}{|c|c|c|c|c|c|}
\hline \multirow[t]{2}{*}{ SNP rs1285933 } & \multirow[t]{2}{*}{ Genotype/allele } & \multicolumn{2}{|l|}{$\mathrm{N}(\%)$} & \multirow[t]{2}{*}{ OR (p-value) } & \multirow[t]{2}{*}{ p-value (IC) } \\
\hline & & Mild & Severe & & \\
\hline & & $62(0.29)$ & $151(0.71)$ & & \\
\hline \multirow{6}{*}{ CLEC5A } & $\mathrm{CC}$ & $19(0.31)$ & $27(0.18)$ & reference & reference \\
\hline & TC & $23(0.37)$ & $83(0.55)$ & $2.75(1.23-6.15)$ & $0.01^{*}$ \\
\hline & TT & $20(0.32)$ & $41(0.27)$ & $1.44(0.62-3.33)$ & 0.40 \\
\hline & $\mathrm{C}$ allele & $61(0.49)$ & $137(0.45)$ & reference & reference \\
\hline & $\mathrm{T}$ allele & $63(0.51)$ & $165(0.55)$ & $1.09(0.64-1.87)$ & 0.74 \\
\hline & T carrier & $43(0.69)$ & $124(0.82)$ & $2.11(1.02-4.40)$ & $0.04^{*}$ \\
\hline
\end{tabular}

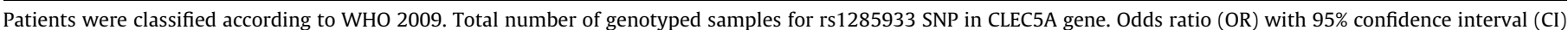
and adjusted for sex, IgG, and age. ${ }^{*} \mathrm{p}<0.05$. 
A

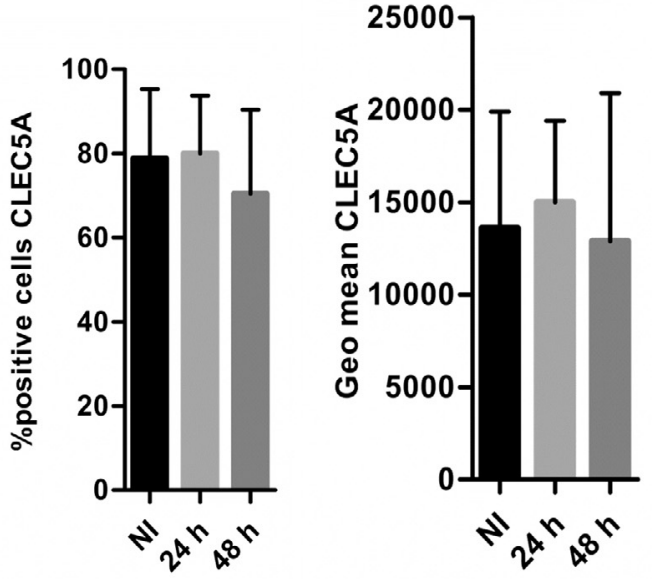

B
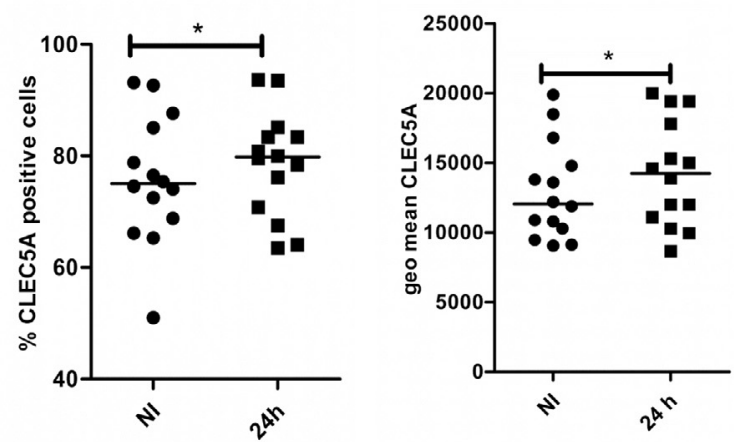

C

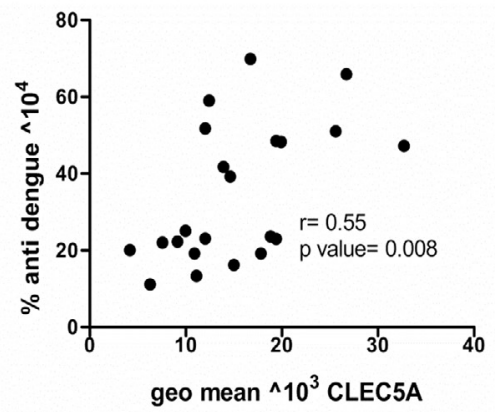

Fig. 1. CLEC5A detection in DENV-infected monocytes. Dengue virus serotype 2 (16681 strain) was used to infect monocytes for 24 or 48 h using a 5:1 MOI. NI, 24-h uninfected cultures. Cells were labeled with anti-human CLEC5A-PE, isotype IgG2b, anti CD14 PerCP, or antibody anti-dengue complex (DENV 1-4) followed by antimouse IgG Alexa Fluor 488 and analyzed by flow cytometry. (A) Median for CLEC5A expression among nine individuals was compared among NI, $24 \mathrm{~h}$, and $48 \mathrm{~h}$ conditions, using the Friedman test. (B) Median CLEC5A expressions (NI and $24 \mathrm{~h}$ ) were compared among monocytes from 13 individuals using Wilcoxon's $t$-test. p $<$ 0.05. (C) DENV-labeled monocytes were positively correlated with CLEC5A expression.

\subsection{CC genotype of rs1285933 SNP showed higher CLEC5A expression}

The CC individuals showed greater CLEC5A production than did the $\mathrm{T}$ carriers (CT/TT) after $24 \mathrm{~h}$ of DENV infection in monocytes, represented either by higher intensity on detection (MIF) or by higher frequencies of CLEC5A-positive cells (Fig. 2A). This effect was not observed after $48 \mathrm{~h}$ of infection (data not shown). There were no differences between DENV loads when comparing the CC vs CT/TT genotypes. Quantification of non-structural protein (NS1) in cell culture supernatants according to genotypes after $24 \mathrm{~h}$ (Fig. 2B) or $48 \mathrm{~h}$ also showed no differences (data not shown). CLEC5A mRNA was also quantified on real-time PCR in whole- blood samples from patients with mild dengue, infected with DENV4. The CC individuals showed a borderline increase in CLEC5A expression compared with the T-carriers $(p=0.08)($ Fig. $2 \mathrm{C})$.

3.4. TNF expression and protein levels were positively correlated with CLEC5A, but not with rs1285933 SNP

After $48 \mathrm{~h}$ of DENV infection in monocytes, TNF levels detected in supernatants were correlated with CLEC5A proteins ( $r=0.72$, $\mathrm{p}=0.03$ ) on the cell surface, analyzed by flow cytometry (Fig. 3A). No correlation was found between CLEC5A and TNF production after $24 \mathrm{~h}$ of infection (data not shown). RNA levels for TNF and CLEC5A were also correlated after $24 \mathrm{~h}$ of dengue infection $(\mathrm{r}=0.78, \mathrm{p}=0.03)$ (Fig. S3).

In the whole-blood samples from the dengue patients, RNA levels for CLEC5A and TNF were positively correlated (Fig. 3B). CLEC5A RNA levels were also correlated with other proinflammatory mediators, such as IL1 $\beta$, IL18, IDO, NLRP3, and TGF $\beta$, and curiously, with anti-inflammatory and antiviral cytokines including IL10, IL15, and IFN $\beta$ (Fig. S4). However, no differences were observed in TNF secretions from monocytes on in vitro assays or in TNF mRNA levels from whole-blood samples according to rs1285933 SNPs (Fig. 3C and D).

\section{Discussion}

The present study shows that CLEC5A, a C-type lectin surface molecule, is upregulated in DENV-infected human circulating monocytes and is correlated with TNF production, as well as with several other mediators in blood samples from dengue patients. CLEC5A has been reported as a central receptor in dengue and other flavivirus infections [10,16,21,34]. The association of rs1285933 SNP with a set of severe alarm signals reinforces our previous results, in which the TT genotype was associated with severe dengue and T-carriers showed a borderline association, in an independent Brazilian population that also included children [10]. However, the present case-case study compared only patients, as the use of mild cases as controls is a common strategy in association studies for complex diseases [35]. We are looking for associations with severity instead of dengue per se, and our previous case-control study performed in southern Brazil (Rio de Janeiro) only included patients with severe dengue [10]. Replication in association studies is important to avoid spurious associations.

Brazilians showed a high admixture rate. Analysis of the EPIGEN database, a project designed to better understand the genetic variability of Brazilians in different areas of the country (Salvador, Bambuí, and Pelotas) [36], showed that the southern populations (Bambuí and Pelotas) had C-allele rates (52\% and 46\%, respectively) very similar to those of Europeans, recovered from 1000 genomes (47\%). On the other hand, in Salvador (northeastern Brazil), the Callele frequency was $34 \%$, as expected, which was similar to that observed in Africans, recovered from 1000 genomes (39\%) (data kindly provided by $\mathrm{Dr}^{\mathrm{a}}$ Fernanda Kehdy and $\mathrm{Dr}^{\circ}$ Eduardo Tarazona-Santos).

Recife is situated in northeastern Brazil, but its population has less African ancestry compared to Salvador [37]. The C-allele frequency there was $47 \%$, while in our previous study from Rio de Janeiro (southern Brazil), the rate was $49 \%$, very close to that observed in Europeans. The frequency of the rs1285933 SNP in different Brazilian populations is consistent with the data obtained here.

The rs1285933 SNP is a singleton (data not shown) when linkage disequilibrium is performed and its neighbor genes belong to olfactory receptor families. Previous studies have shown upregulation of CLEC5A after dengue infections $[16,38]$ and the rs1285933 
A

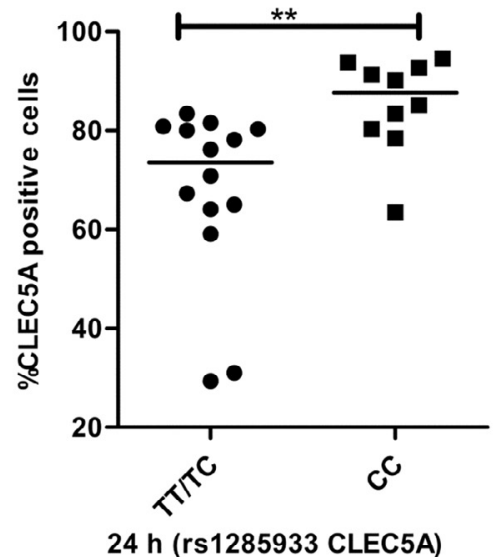

B
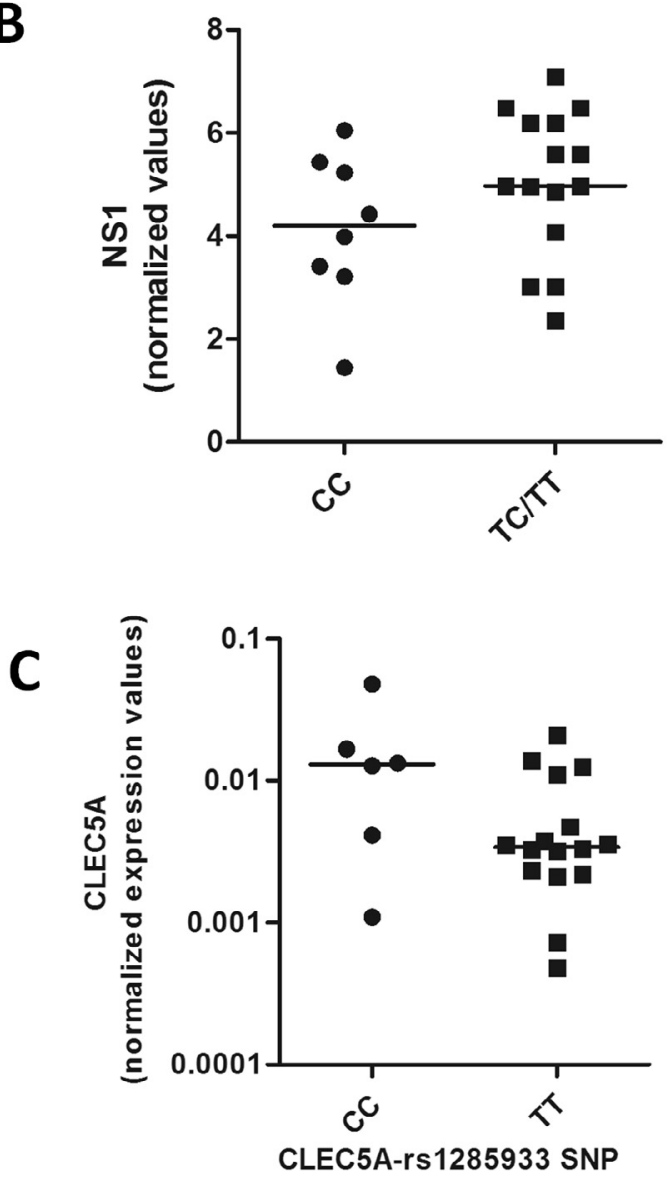
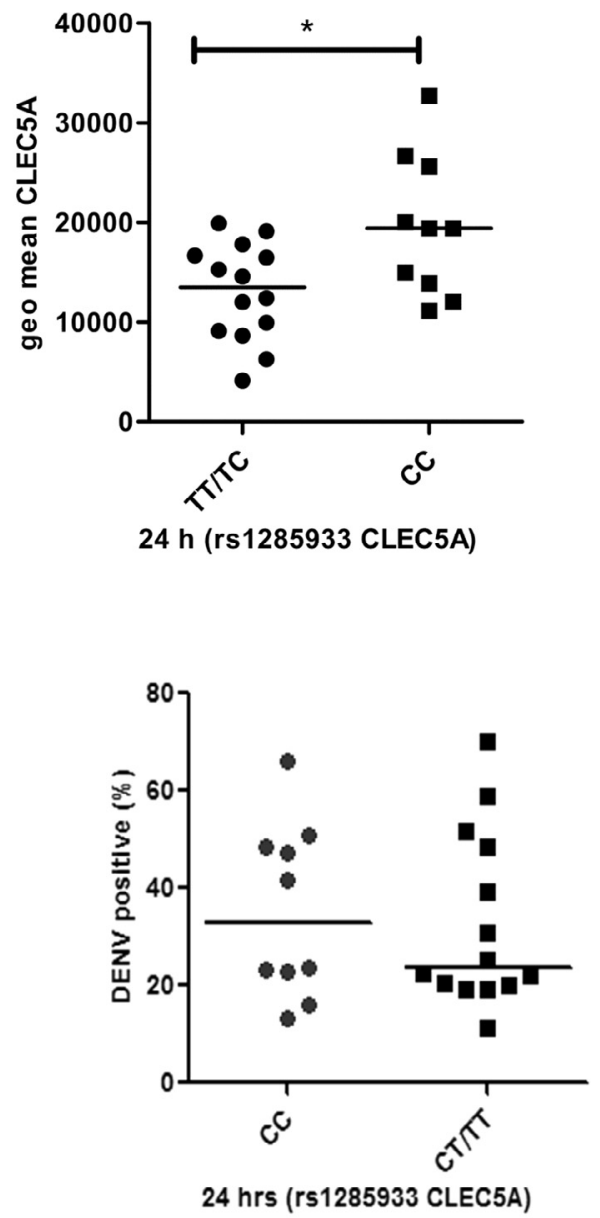

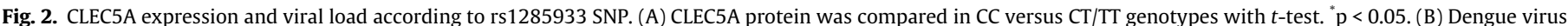

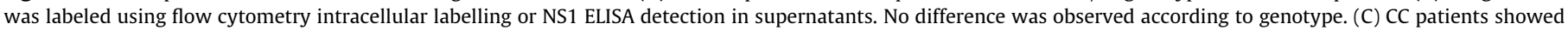
increased borderline expression $(\mathrm{p}=0.08)$ in RNA levels compared with T-carriers.

SNP has been reported as a quantitative trait locus (eQTL) for CLEC5A [39]. Our results suggest that the rs1285933 SNP may be an eQTL for dengue-stimulated monocytes. However, surprisingly, the CT/TT genotypes associated with severity risk were also associated with lower levels of CLEC5A. It has been suggested that DAP12 can display inhibitory or stimulatory activity depending on the binding avidity between the receptor associated with DAP12 (CLEC5A, in this case) and its ligand [17]. It is likely that during high-avidity ligation, DAP12 is fully activated and can synergize with other pathways, such as the toll-like receptor (TLR) pathway. In contrast, during partial DAP12 activation, the signaling follows an inhibitory pathway [17].

Weak binding has been demonstrated between the dengue virus and CLEC5A $[40,41]$. We could therefore hypothesize that when CLEC5A is less expressed (CT/TT) and partial DAP12 activation is at work, an inefficient immune response occurs. However, the CC genotype would be associated with protection from severe dengue by activating a better response through full DAP12 
A

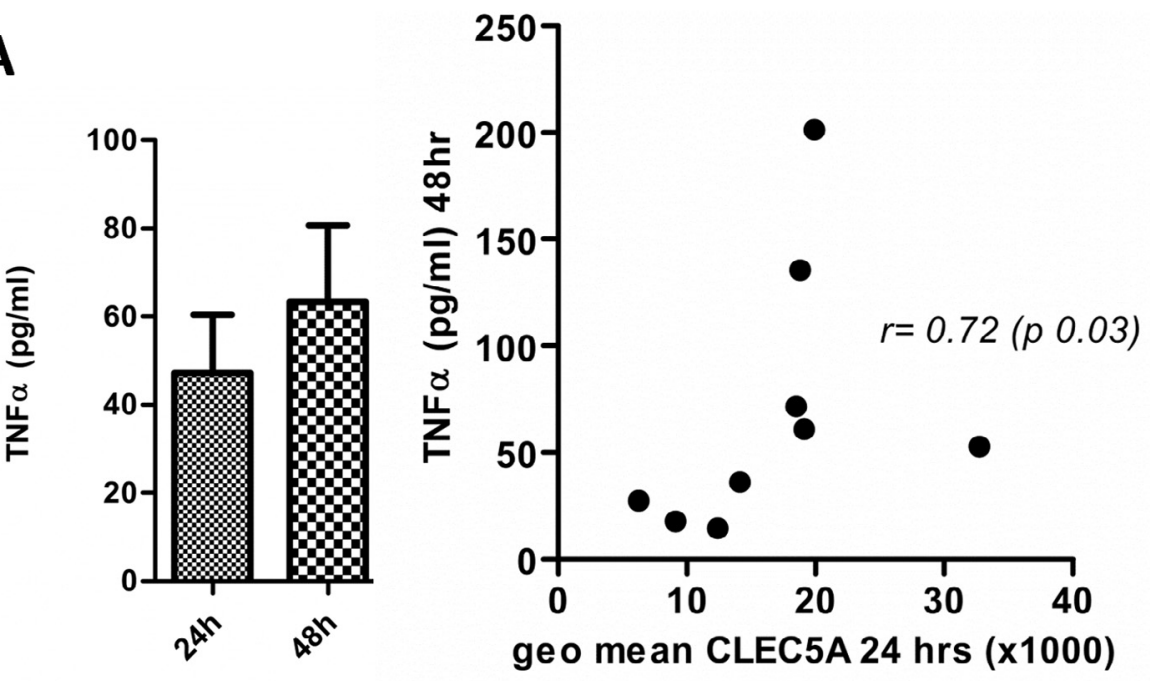

B

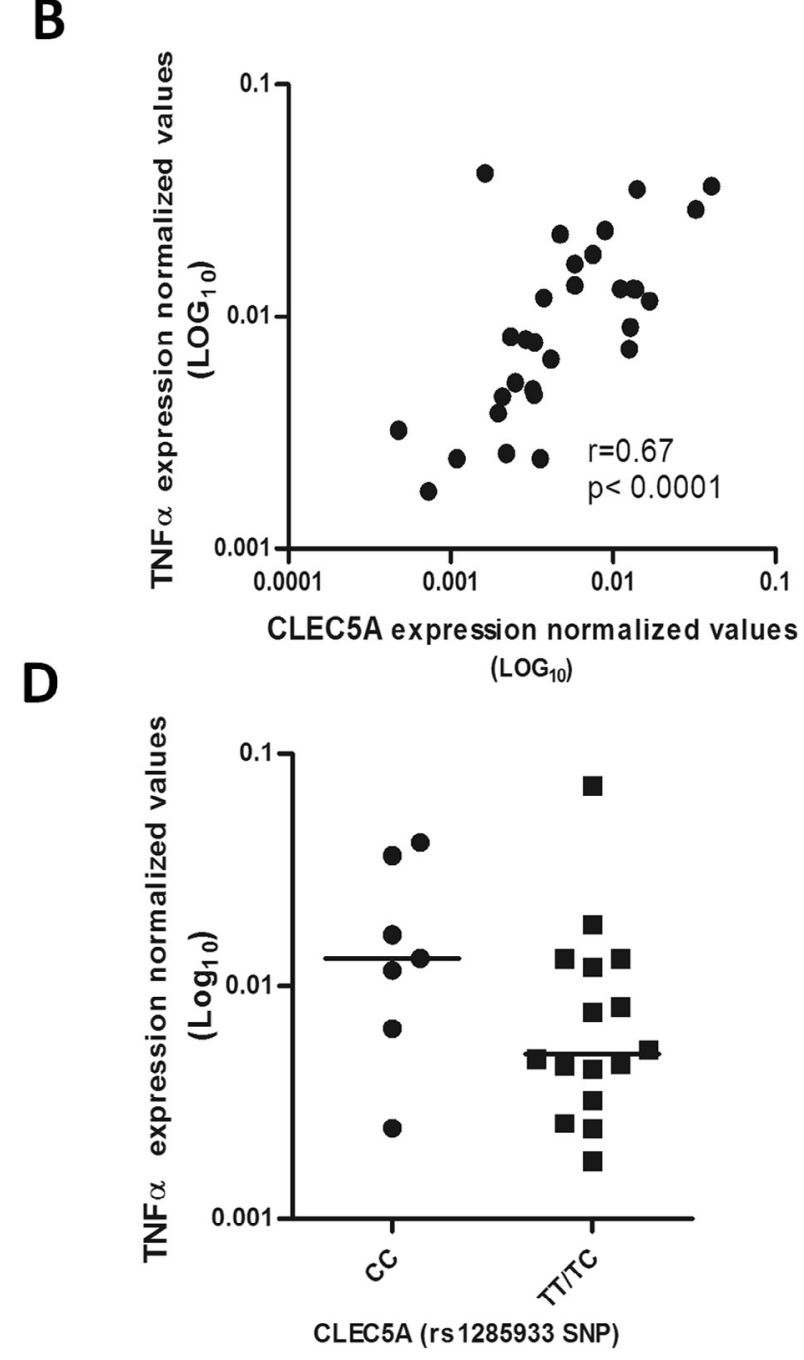

C

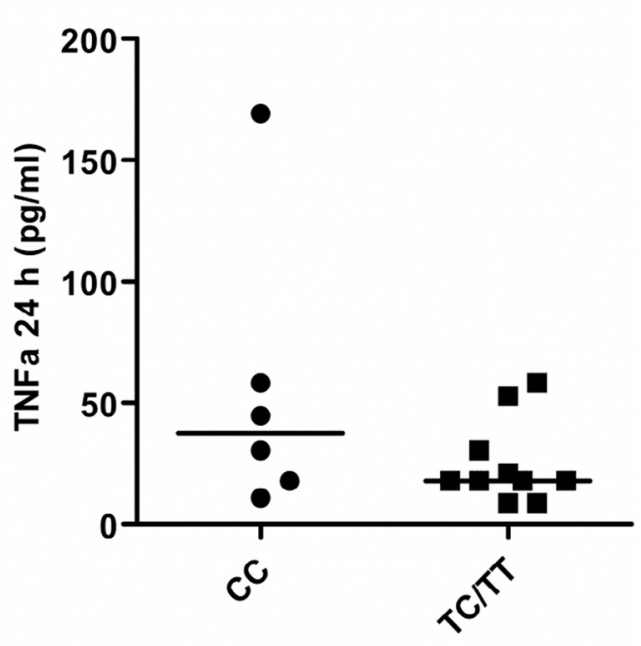

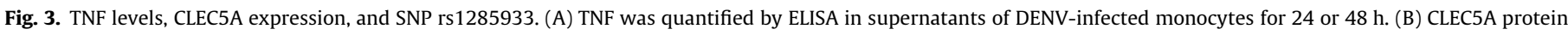

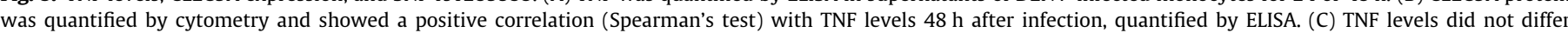
according to genotype in in vitro infections or protein detection by ELISA or (D) mRNA detection in whole-blood samples.

signaling and possible synergy with other antiviral pathways, such as TLRs. Furthermore, the canonical DAP12 pathway produces proinflammatory cytokines but there are also indications of DAP12 involvement in anti-inflammatory pathways $[42,43]$.
Another hypothesis is that other SNPs can contribute to the observed functional effects. A recent study showed the synergistic effect between DCSIGN and mannose receptor (MR) with CLEC5ADAP12 signaling $[40,44]$. However, the mechanisms involved in 
DAP12 signaling after DENV binding are unknown. DCSIGN and MR are crucial receptors for dengue infection in monocytes and dendritic cells. SNPs in these genes could influence the DENV binding avidity and, consequently, DAP12 signaling.

The present study failed to confirm that rs1285933 is associated with TNF levels in vitro or in vivo, although we previously showed that serum TNF levels were higher among rs1285933T-carriers [10]. The inability to confirm our previous data could be due to different sources, as this cytokine was previously quantified only in serum [10]. Here, we used only supernatants from purified monocytes or whole blood (for mRNA detection) of dengue patients; other cells may have also been involved in serum TNF secretion. It is important to highlight that this case-only genetic epidemiological study was performed on children and with in vitro functional experiments for adults. Moreover, patients enrolled for the in vivo functional analysis presented with mild dengue fever caused by DENV4. These differences could affect the results.

In summary, the results shown here highlight the important role of CLEC5A in dengue immunopathogenesis and the participation of the rs1285933 SNP in signaling pathways after CLEC5ADAP12 activation. The findings can be extended to febrile infections caused by other arboviruses with poorly understood immunopathogenesis, such as Zika, chikungunya, West Nile, and Japanese encephalitis.

\section{Conflict of interest}

There is no conflict of interest.

\section{Funding}

The authors wish to thank the Agency for Science Development of Pernambuco State (FACEPE), the Agency for Research Support of Rio de Janeiro State (FAPERJ), and the Oswaldo Cruz Institute (IOC)-Oswaldo Cruz Foundation (FIOCRUZ). We also thank Scribendi for manuscript proofreading and editing.

\section{Acknowledgments}

We are grateful to $\mathrm{Dr}^{\circ}$ Leonardo Ribeiro for critical reading of the paper, and to $\mathrm{Dr}^{\mathrm{a}}$ Fernanda Kehdy and $\mathrm{Dr}^{\circ}$ Eduardo TarazonaSantos for the EPIGEN analysis.

\section{Appendix A. Supplementary data}

Supplementary data associated with this article can be found, in the online version, at http://dx.doi.org/10.1016/j.humimm.2017. 07.013.

\section{References}

[1] D. Musso, V.M. Cao-Lormeau, D.J. Gubler, Zika virus: following the path of dengue and chikungunya?, Lancet 386 (2016) 243-244, http://dxdoi.org/ 10.1016/S0140-6736(15)61273-9.

[2] WHO, Dengue: guidelines for diagnosis, treatment, prevention, and control, Spec. Program. Res. Train. Trop. Dis. (2009) 147. doi: http://dx.doi.org/WHO/ HTM/NTD/DEN/2009.1.

[3] S. Bhatt, P.W. Gething, O.J. Brady, J.P. Messina, A.W. Farlow, C.L. Moyes, J.M. Drake, J.S. Brownstein, A.G. Hoen, O. Sankoh, M.F. Myers, D.B. George, T. Jaenisch, G.R.W. Wint, C.P. Simmons, T.W. Scott, J.J. Farrar, S.I. Hay, The global distribution and burden of dengue, Nature 496 (2013) 504-507, http://dx.doi. org/10.1038/nature 12060 .

[4] A. Balmaseda, S.N. Hammond, L. Pérez, Y. Tellez, S.I. Saborío, J.C. Mercado, R. Cuadra, J. Rocha, M.A. Pérez, S. Silva, C. Rocha, E. Harris, Serotype-specific differences in clinical manifestations of dengue, Am. J. Trop. Med. Hyg. 74 (2006) 449-456, 74/3/449.

[5] S.B. Halstead, N.T. Lan, T.T. Myint, T.N. Shwe, A. Nisalak, S. Kalyanarooj, S. Nimmannitya, S. Soegijanto, D.W. Vaughn, T.P. Endy, Dengue hemorrhagic fever in infants: Research opportunities ignored, Emerg. Infect. Dis. 8 (2002) 1474-1479, http://dx.doi.org/10.3201/eid0812.020170.
[6] C.C. Lin, Y.H. Huang, P.Y. Shu, H.S. Wu, Y.S. Lin, T.M. Yeh, H.S. Liu, C.C. Liu, H.Y. Lei, Characteristic of dengue disease in Taiwan: 2002-2007, Am. J. Trop. Med. Hyg. 82 (2010) 731-739, http://dx.doi.org/10.4269/ajtmh.2010.09-0549.

[7] N.T. Hung, H.-Y. Lei, N.T. Lan, Y.-S. Lin, K.-J. Huang, L.B. Lien, C.-F. Lin, T.-M. Yeh, D.Q. Ha, V.T.Q. Huong, L.-C. Chen, J.-H. Huang, L.T. My, C.-C. Liu, S.B. Halstead, Dengue hemorrhagic fever in infants: a study of clinical and cytokine profiles, J. Infect. Dis. 189 (2004) 221-232, http://dx.doi.org/10.1086/380762.

[8] X. Fang, Z. Hu, W. Shang, J. Zhu, C. Xu, X. Rao, Genetic polymorphisms of molecules involved in host immune response to dengue virus infection, FEMS Immunol. Med. Microbiol. 66 (2012) 134-146, http://dx.doi.org/10.1111/ j.1574-695X.2012.00995.x.

[9] H.A.F. Stephens, HLA and Other Gene Associations with Dengue Disease Severity BT - Dengue Virus, Springer, Berlin, Heidelberg, 2010, pp. 99-114, http://dx.doi.org/10.1007/978-3-642-02215-9_8.

[10] C. Xavier-Carvalho, G. Gibson, P. Brasil, R.X. Ferreira, R. De Souza, Santos, O. Gonçalves Cruz, S.A. De Oliveira, M. De Sá Carvalho, A.G. Pacheco, C.F. Kubelka, M.O. Moraes, Single nucleotide polymorphisms in candidate genes and dengue severity in children: A case-control, functional and meta-analysis study, Infect. Genet. Evol. 20 (2013) 197-205, http://dx.doi.org/10.1016/j.meegid.2013. 08.017.

[11] R. Thamizhmani, P. Vijayachari, Brief communication Association of dengue virus infection susceptibility with polymorphisms of 2-5-oligoadenylate synthetase genes : a case - control study, Brazilian J. Infect. Dis. 8 (2014) 46, http://dx.doi.org/10.1016/j.bjid.2014.03.004.

[12] G.G. Figueiredo, R.D. Cezar, N.M. Freire, V.G. Teixeira, P. Baptista, M. Cordeiro, R.F. Carmo, L.R.S. Vasconcelos, P. Moura, Mannose-binding lectin gene (MBL2) polymorphisms related to the mannose-binding lectin low levels are associated to dengue disease severity, Hum. Immunol. 77 (2016) 571-575, http://dx.doi.org/10.1016/j.humimm.2016.05.006.

[13] C.C. Khor, T.N.B. Chau, J. Pang, S. Davila, H.T. Long, R.T.H. Ong, S.J. Dunstan, B. Wills, J. Farrar, T. Van Tram, T.T. Gan, N.T.N. Binh, L.T. Tri, L.B. Lien, N.M. Tuan, N.T.H. Tham, M.N. Lanh, N.M. Nguyet, N.T. Hieu, N. Van, N. Vinh Chau, T.T. Thuy, D.E.K. Tan, A. Sakuntabhai, Y.-Y. Teo, M.L. Hibberd, C.P. Simmons, Genome-wide association study identifies susceptibility loci for dengue shock syndrome at MICB and PLCE1, Nat. Genet. 43 (2011) 1139-1141, http://dx.doi. org/10.1038/ng.960.

[14] A.A. Watson, A.A. Lebedev, B.A. Hall, A.E. Fenton-May, A.A. Vagin, W. Dejnirattisai, J. Felce, J. Mongkolsapaya, A.S. Palma, Y. Liu, T. Feizi, G.R. Screaton, G.N. Murshudov, C.A. O'Callaghan, Structural flexibility of the macrophage dengue virus receptor CLEC5A: implications for ligand binding and signaling, J. Biol. Chem. 286 (2011) 24208-24218, http://dx.doi.org/ 10.1074/jbc.M111.226142.

[15] A.B. Bakker, E. Baker, G.R. Sutherland, J.H. Phillips, L.L. Lanier, Myeloid DAP12associating lectin (MDL)-1 is a cell surface receptor involved in the activation of myeloid cells, Proc. Natl. Acad. Sci. U.S.A. 96 (1999) 9792-9796, http://dx. doi.org/10.1073/pnas.96.17.9792.

[16] S.-T. Chen, Y.-L. Lin, M.-T. Huang, M.-F. Wu, S.-C. Cheng, H.-Y. Lei, C.-K. Lee, T.W. Chiou, C.-H. Wong, S.-L. Hsieh, CLEC5A is critical for dengue-virus-induced lethal disease, Nature 453 (2008) 672-676, http://dx.doi.org/ 10.1038/nature07013.

[17] I.R. Turnbull, M. Colonna, Activating and inhibitory functions of DAP12, Nat. Rev. Immunol. 7 (2007) 155-161.

[18] A. Paradowska-Gorycka, M. Jurkowska, Structure, expression pattern and biological activity of molecular complex TREM-2/DAP12, Hum. Immunol. 74 (2013) 730-737, http://dx.doi.org/10.1016/j.humimm.2013.02.003.

[19] E. Vivier, J.A. Nunès, F. Vély, Natural killer cell signaling pathways, Science 306 (2004) 1517-1519, 80-

[20] B. Pasquier, P. Launay, Y. Kanamaru, I.C. Moura, S. Pfirsch, C. Ruffié, D. Hénin, M. Benhamou, M. Pretolani, U. Blank, R.C. Monteiro, Identification of Fc $\alpha$ RI as an inhibitory receptor that controls inflammation: dual role of FCR $\gamma$ ITAM, Immunity 22 (2005) 31-42, http://dx.doi.org/10.1016/j.immuni.2004.11.017.

[21] M. Wu, S. Chen, A. Yang, W. Lin, Y. Lin, N. Chen, I. Tsai, L. Li, CLEC5A is critical for dengue virus - induced inflammasome activation in human macrophages, Blood 121 (2013) 95-106, http://dx.doi.org/10.1182/blood-2012-05-430090.

[22] B. Joyce-Shaikh, M.E. Bigler, C.-C. Chao, E.E. Murphy, W.M. Blumenschein, I.E Adamopoulos, P.G. Heyworth, S. Antonenko, E.P. Bowman, T.K. McClanahan, J. H. Phillips, D.J. Cua, Myeloid DAP12-associating lectin (MDL)-1 regulates synovial inflammation and bone erosion associated with autoimmune arthritis, J. Exp. Med. 207 (2010) 579-589, http://dx.doi.org/10.1084/jem. 20090516.

[23] R. Cheung, F. Shen, J.H. Phillips, M.J. McGeachy, D.J. Cua, P.G. Heyworth, R.H. Pierce, Activation of MDL-1 (CLEC5A) on immature myeloid cells triggers lethal shock in mice, J. Clin. Invest. 121 (2011) 4446-4461, http://dx.doi.org/ 10.1172/JCI57682.

[24] P.A. Ward, Do MDL-1 + cells play a broad role in acute inflammation?, J Clin. Invest. 121 (2011) 4234-4237, http://dx.doi.org/10.1172/JCI60122.

[25] A. Torrentes-Carvalho, E.D. Hottz, C.F. Marinho, J.B.-C. da Silva, L.M. de Oliveira Pinto, L.G. Fialho, F.A. Bozza, R.V. Cunha, P.V. Damasco, C.F. Kubelka, E.L. de Azeredo, Characterization of clinical and immunological features in patients coinfected with dengue virus and HIV, Clin. Immunol. 164 (2016) 95-105, http://dx.doi.org/10.1016/j.clim.2016.01.005.

[26] M. Gandini, C. Gras, E.L. Azeredo, L.M.D.O. Pinto, N. Smith, P. Despres, R.V. da Cunha, L.J. de Souza, C.F. Kubelka, J.P. Herbeuval, Dengue virus activates membrane TRAIL relocalization and IFN- $\alpha$ Production by human plasmacytoid dendritic cells in vitro and in vivo, PLoS Negl. Trop. Dis. 7 (2013), http://dx.doi. org/10.1371/journal.pntd.0002257. 
ARTICLE IN PRESS

8

C. Xavier-Carvalho et al./Human Immunology $x x x$ (2017) $x x x-x x x$

[27] S.B. Halstead, N.J. Marchette, Biologic properties of dengue viruses following serial passage in primary dog kidney cells: studies at the University of Hawaii, Am. J. Trop. Med. Hyg. 69 (2003) 5-11 (accessed September 9, 2015).

[28] H. Reed, L.J. Muench, A simple method of estimating fifty percent endpoints, Am. J. Hyg. 27 (1938) 493-497.

[29] S. Inoue, M.T.G. Alonzo, Y. Kurosawa, C.A. Mapua, J.D. Reyes, E.M. Dimaano, M. T.P. Alera, M. Saito, K. Oishi, F. Hasebe, R.R. Matias, F.F. Natividad, K. Morita, Evaluation of a dengue IgG indirect enzyme-linked immunosorbent assay and a Japanese encephalitis IgG indirect enzyme-linked immunosorbent assay for diagnosis of secondary dengue virus infection, Vector-Borne Zoonotic Dis. 10 (2009) 143-150, http://dx.doi.org/10.1089/vbz.2008.0153.

[30] G. Chang, A.V. Vorndamt, Rapid detection and typing of dengue viruses from clinical samples by using reverse transcriptase-polymerase chain reaction, J. Clin. Microbiol. 30 (1992) 545-551.

[31] N.R. Faria, V.E. Solorzano, R.M. Nogueira, T. Chouin-Carneiro, P.C. Nunes, J.B. Simoes, F. de Bruycker Nogueira, R. Lima Mda, L.M. de Oliveira Pinto, C.F. Kubelka, R.V. Dacunha, E.L. de Azeredo, F.B. dos Santos, Dengue epidemics in two distinct periods reveal distinct epidemiological, laboratorial and clinical aspects in a same scenario: analysis of the 2010 and 2013 epidemics in Mato Grosso do Sul, Brazilo Title, Trans. R. Soc. Trop. Med. Hyg. 110 (2016) 228-236.

[32] L.T.A. Guerreiro, A.B. Robottom-Ferreira, M. Ribeiro-Alves, T.G. Toledo-Pinto, T. Rosa Brito, P.S. Rosa, F.G. Sandoval, M.R. Jardim, S.G. Antunes, E.J. Shannon, E.N. Sarno, M.C.V. Pessolani, D.L. Williams, M.O. Moraes, Gene expression profiling specifies chemokine, mitochondrial and lipid metabolism signatures in leprosy, PLoS One 8 (2013), http://dx.doi.org/10.1371/journal.pone.0064748.

[33] R.A.L. and E. for S. Development - Core Team, C.R.F. for S. Computing, A Language and Environment for Statistical Computing. R Foundation for Statistical Computing, (2008).

[34] S.T. Chen, R.S. Liu, M.F. Wu, Y.L. Lin, S.Y. Chen, D.T.W. Tan, T.Y. Chou, I.S. Tsai, L. Li, S.L. Hsieh, CLEC5A regulates Japanese encephalitis virus-induced neuroinflammation and lethality, PLoS Pathog. 8 (2012), http://dx.doi.org/ 10.1371/journal.ppat.1002655.

[35] A.G. Pacheco, M.O. Moraes, Genetic polymorphisms of infectious diseases in case-control studies, Dis. Markers 27 (2009) 173-186, http://dx.doi.org/ 10.3233/DMA-2009-0654.
[36] F.S.G. Kehdy, M.H. Gouveia, M. Machado, W.C.S. Magalhães, A.R. Horimoto, Origin and dynamics of admixture in Brazilians and its effect on the pattern of deleterious mutations, Proc. Natl. Acad. Sci. U.S.A. 112 (2015) 8696-8701, http://dx.doi.org/10.1073/pnas.1504447112.

[37] A.V.C. Coelho, R.R. Moura, C.A.J. Cavalcanti, R.L. Guimarães, A rapid screening of ancestry for genetic association studies in an admixed population from Pernambuco, Brazil 14 (2015) 2876-2884.

[38] Y. Cheng, Y. Lin, C. Chen, T. Tsai, C. Tsai, Y. Wu, Y. Ou, Y. Chu, J. Wang, C. Yu, C. Lin, Activation of Nrf2 by the dengue virus causes an increase in CLEC5A, which enhances TNF- $\alpha$ production by mononuclear phagocytes, Nat. Publ. Gr. (2016) 1-15, http://dx.doi.org/10.1038/srep32000.

[39] T. Zeller, P. Wild, S. Szymczak, M. Rotival, A. Schillert, R. Castagne, S. Maouche, M. Germain, K. Lackner, H. Rossmann, M. Eleftheriadis, C.R. Sinning, R.B. Schnabe, E. Lubos, D. Mennerich, W. Rust, C. Perret, C. Proust, V. Nicaud, J. Loscalzo, N. H??bner, D. Tregouet, T. M??nze, A. Ziegler, L. Tiret, S. Blankenberg, F. Cambien, Genetics and beyond - the transcriptome of human monocytes and disease susceptibility, PLoS One 5 (2010), http://dx.doi.org/ 10.1371/journal.pone.0010693.

[40] Y.-L. Lo, G.-G. Liou, J.-H. Lyu, M. Hsiao, T.-L. Hsu, C.-H. Wong, Dengue virus infection Is through a cooperative interaction between a mannose receptor and CLEC5A on macrophage as a multivalent hetero-complex, PLoS One 11 (2016) e0166474.

[41] Y.T. Tung, M.F. Wu, G.J. Wang, S.L. Hsieh, Nanostructured electrochemical biosensor for th0065 detection of the weak binding between the dengue virus and the CLEC5A receptor, Nanomed. Nanotechnol. Biol. Med. 10 (2014) 13351341, http://dx.doi.org/10.1016/j.nano.2014.03.009.

[42] C. Ho, Y. Fong, M. Bebien, A. Didierlaurent, R. Nebauer, T. Hussell, D. Broide, M. Karin, T. Lawrence, An antiinflammatory role for IKK $\beta$ through the inhibition of “classical" macrophage activation, J. Exp. Med. 205 (2008) 1269-1276, http:// dx.doi.org/10.1084/jem.20080124.

[43] T. Lawrence, Inflammation (2009) 1-10.

[44] Y. Lo, G. Liou, J. Lyu, M. Hsiao, T. Hsu, Dengue virus infection is through a cooperative interaction between a mannose receptor and CLEC5A on macrophage as a multivalent hetero-complex, PLoS One (2016) 1-13, http:// dx.doi.org/10.1371/journal.pone.0166474.

Please cite this article in press as: C. Xavier-Carvalho et al., Association of rs1285933 single nucleotide polymorphism in CLEC5A gene with dengue severity

and its functional effects, Hum. Immunol. (2017), http://dx.doi.org/10.1016/j.humimm.2017.07.013 